\title{
MODELO DE SUSCETIBILIDADE À EROSÃO APLICADO AO GERENCIAMENTO DE LINHAS FÉRREAS. ESTUDO DE CASO: MALHA PAULISTA - SP (BACIA DO TIETÊ - SOROCABA)
}

\section{EROSION SUSCEPTIBILITY MODEL APPLIED TO THE MANAGEMENT OF RAILWAYS. CASE STUDY: TIETE - SOROCABA HYDROGRAPHIC BASIN TRAIN NETWORK}

\author{
Natália Costa SOUZA ${ }^{1}$, José Augusto LOLLO², Gerson Salviano ALMEIDA FILHO ${ }^{3}$ \\ ${ }^{1}$ Universidade Federal de São Carlos. Centro de Ciências Exatas e de Tecnologia, Departamento de Engenharia Civil. Rodovia \\ Washington Luis, km 235, Área Norte. Jardim Guanabara. São Carlos, São Paulo. Brasil. Email: nataliacostaptr@usp.br \\ ${ }^{2}$ Universidade Estadual Paulista. Faculdade de Engenharia de Ilha Solteira Av. Brasil Sul, 56 - Centro, Ilha Solteira - SP, Brasil. \\ Email: jose.lollo@unesp.br \\ ${ }^{3}$ Instituto de Pesquisas Tecnológicas. Laboratório de Riscos Ambientais - Av. Professor Almeida Prado, no 532, São Paulo - SP - \\ Brasil. Email gersaf@ipt.br

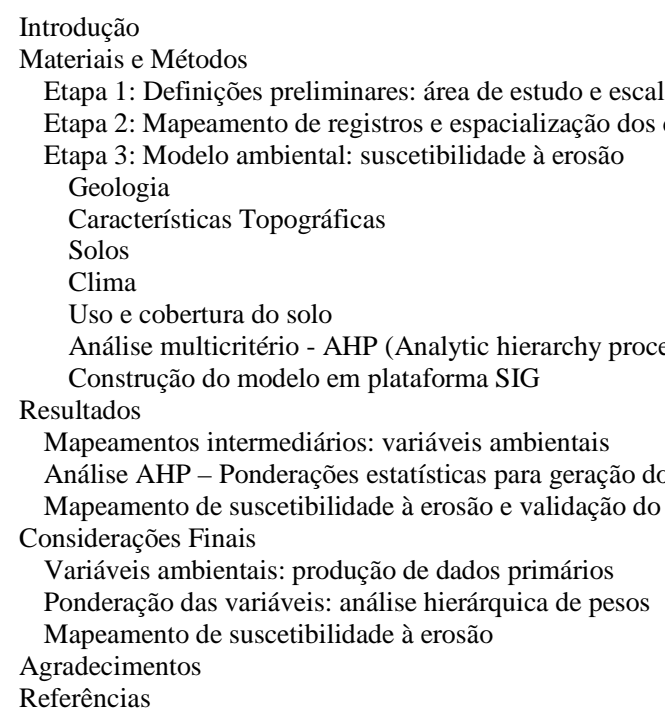

RESUMO - A ocorrência de eventos erosivos acelerados associados à implantação de sistemas de transportes é um dos principais problemas socioambientais enfrentados pelas concessionárias brasileiras. Os estudos relativos às análises de dinâmica de desenvolvimento e à ocorrência de processos erosivos estão inseridos em abordagens ambientais teórico-metodológicas consagradas nas áreas de Geociências. Nas mais variadas abordagens capazes de subsidiar processos de análise, monitoramento e controle de riscos ambientais, técnicas estatísticas de análises multivariadas de dados associadas à utilização de sistemas de informações geográficas (SIG) têm sido ferramentas amplamente utilizadas. Nesse contexto, a pesquisa propõe a combinação do uso de geotecnologias e Análise Multivariada de Dados (Análise Hierárquica de Pesos - AHP) para análise dos níveis de suscetibilidade à erosão no terreno que corresponde ao entorno da linha férrea Malha Paulista, uma das principais ferrovias do país. Os resultados fornecem a leitura das características ambientais do terreno selecionadas para composição do indicador e a análise da quantificação das áreas classificadas em níveis de suscetibilidade. A obtenção de informações que validassem o resultado final do indicador foi um diferencial da pesquisa. Baseado no total de processos erosivos analisados e nas classes de suscetibilidade definidas, é possível afirmar que o mapeamento final apresentou precisão de 91,36\%.

Palavras-chave: Erosão, Linhas Férreas, Geotecnologias, Sistemas de Informações Geográficas (SIG), Análise Hierárquica de Pesos.

ABSTRACT - The occurrence of accelerated erosive events associated to the implantation of transport systems is one of the main socioenvironmental problems encountered by brazilian concessionaires. Studies related to the analyzes of development dynamics of erosive processes are inserted in theoretical and methodological consecrated environmental approaches in the areas of Geosciences. In several areas of knowledge and in the most varied approaches able of supporting processes of analysis, monitoring and control of environmental risks, statistical techniques of multivariate data analysis associated with the use of geographic information systems have been widely used tools. This research proposes the combination of the use of geotechnologies and Multivariate Data Analysis to analyze the levels of susceptibility to erosion in the terrain corresponding to the surroundings of the Malha Paulista railway. The results provided the reading of the selected soil environmental characteristics for the composition of the indicator and the analysis of the quantification of the areas classified into levels of susceptibility. Obtaining information that validated the final result of the indicator was a differential of the research. Based on the total erosive processes analyzed and on the defined susceptibility classes, it is possible to state that the final mapping presented a precision of $91.36 \%$.

Keywords: Erosion, Railways, Geotechnologies, Geographic Information Systems (GIS), Hierarchical Process Analysis. 


\section{INTRODUÇÃO}

De acordo com a Política Ambiental do Ministério dos Transportes (artigo 225, § $1^{\circ}$, inciso V), as atividades ferroviárias (construção, manutenção, duplicação, transporte) enquadramse na definição de atividades potencialmente causadoras de significativa degradação do meio ambiente, sendo amplamente recepcionadas pelos instrumentos constitucionais. No Brasil, para processos de licenciamento ambiental e regularização dos empreendimentos ferroviários em operação, o Instituto Brasileiro do Meio Ambiente e dos Recursos Renováveis (IBAMA) prevê a implantação de planos e programas ambientais que alcancem o cumprimento das condicionantes necessárias à regularização e funcionamento adequado das atividades em operação no país.

Tais programas visam à minimização de danos provenientes da operação da malha, resultando no gerenciamento eficaz dos riscos de suas atividades, possibilitando a mitigação em caso de eventuais impactos aos meios físicos, bióticos e socioeconômicos.

Dessa forma, um dos aspectos abordados dentre os programas exigidos é a análise das ocorrências de processos erosivos ao longo da faixa de domínio da malha, o diagnóstico da gravidade dos processos, as características do terreno relacionadas às possibilidades de desenvolvimento e agravamento dos processos, a espacialização e padrões de distribuição dos eventos registrados, ações de prevenção, recuperação das áreas afetadas e riscos oferecidos.

Em geral, na literatura, os estudos relativos as análises de dinâmica de desenvolvimento e à ocorrência de processos erosivos estão inseridos em abordagens ambientais teóricometodológicas consagradas nas áreas de Geociências e Engenharias. Em diversas áreas do conhecimento e nas mais variadas abordagens capazes de subsidiar processos de análise, monitoramento e controle de riscos ambientais, técnicas estatísticas de análises multivariadas de dados associadas à utilização de sistemas de informações geográficas (SIG) têm sido ferramentas amplamente utilizadas (Souza et al., 2017; Hyun-joo Oh \& Biswajeet, 2011; Pradhan \& Lee, 2010; Pourghasemi et al., 2012; Devkota et al., 2013; Bui et al., 2012; Regmi et al., 2014; Corrêa et al., 2007; Castro et al., 2006; Burroughs \& King, 1989; Kochenderter, 1970).

Tais aplicações consistem em uma das principais ferramentas e formas de avaliação utilizadas por pesquisadores e especialistas da área, por órgãos federais e estaduais e departamentos públicos e privados na elaboração das etapas de diagnósticos preliminares, análise ambiental, territorial, planejamento e monitoramento. No que tange ao desenvolvimento de metodologias e modelagens de análise ambientais associadas à ocorrência e à dinâmica de processos erosivos, tais estudos geram ferramentas de predição de cenários, medidas de probabilidade ou classificações qualitativas dos terrenos quanto ao grau de suscetibilidade ou vulnerabilidade das áreas para ocorrência dos mesmos (Souza et al., 2017).

A área de estudo do presente trabalho é parte da bacia do Tietê-Sorocaba, região por onde percorre a Malha Paulista, operada pela concessionária América Latina Logística - ALL, uma das principais vias férreas do estado de São Paulo. A pesquisa se valeu da combinação do uso de geotecnologias e análise multivariada de dados (Análise Hierárquica de Pesos - AHP) para análise dos níveis de suscetibilidade do terreno ao longo do traçado da malha.

A contribuição essencial da pesquisa trata-se da proposta para monitoramento de erosões em linhas férreas ou outros tipos de empreendimentos lineares. Além disso, explora o uso de geoprocessamento e análise multivariada de dados. Assim, dois objetivos foram considerados: (1) propor e testar um modelo de classificação do terreno quanto aos níveis de suscetibilidade à erosão; (2) apresentar técnica de fácil interpretação para este propósito.

\section{MATERIAIS E MÉTODOS}

Os procedimentos metodológicos dividem-se em quatro etapas distintas, conforme ilustra a figura abaixo (Figura 1). Os materiais utilizados e a descrição de cada etapa seguem na sequência.

\section{Etapa 1: Definições preliminares: área de estudo e escala de trabalho}

A região de interesse (Figura 2) é restrita às análises e registros de processos erosivos diagnosticados no trecho que interliga as cidades 
de Mairinque (SP) a Botucatu (SP), totalizando um trajeto de aproximadamente $176 \mathrm{~km}$. Judicialmente, a faixa situada à margem da ferrovia, chamada faixa de domínio, é uma área de terreno com pequena largura em relação à extensão da linha e varia de acordo com cada trecho em todo o território nacional. Dessa forma, optou-se por gerar o mapeamento de suscetibilidade na porção de área pertencente a um buffer (área de influência) de $5 \mathrm{~km}$ de abrangência ao longo do traçado da malha. A escolha da área de interesse deu-se por conta da importância econômica da linha e frequência de registros de impactos negativos gerados pela ocorrência de fenômenos erosivos na região.

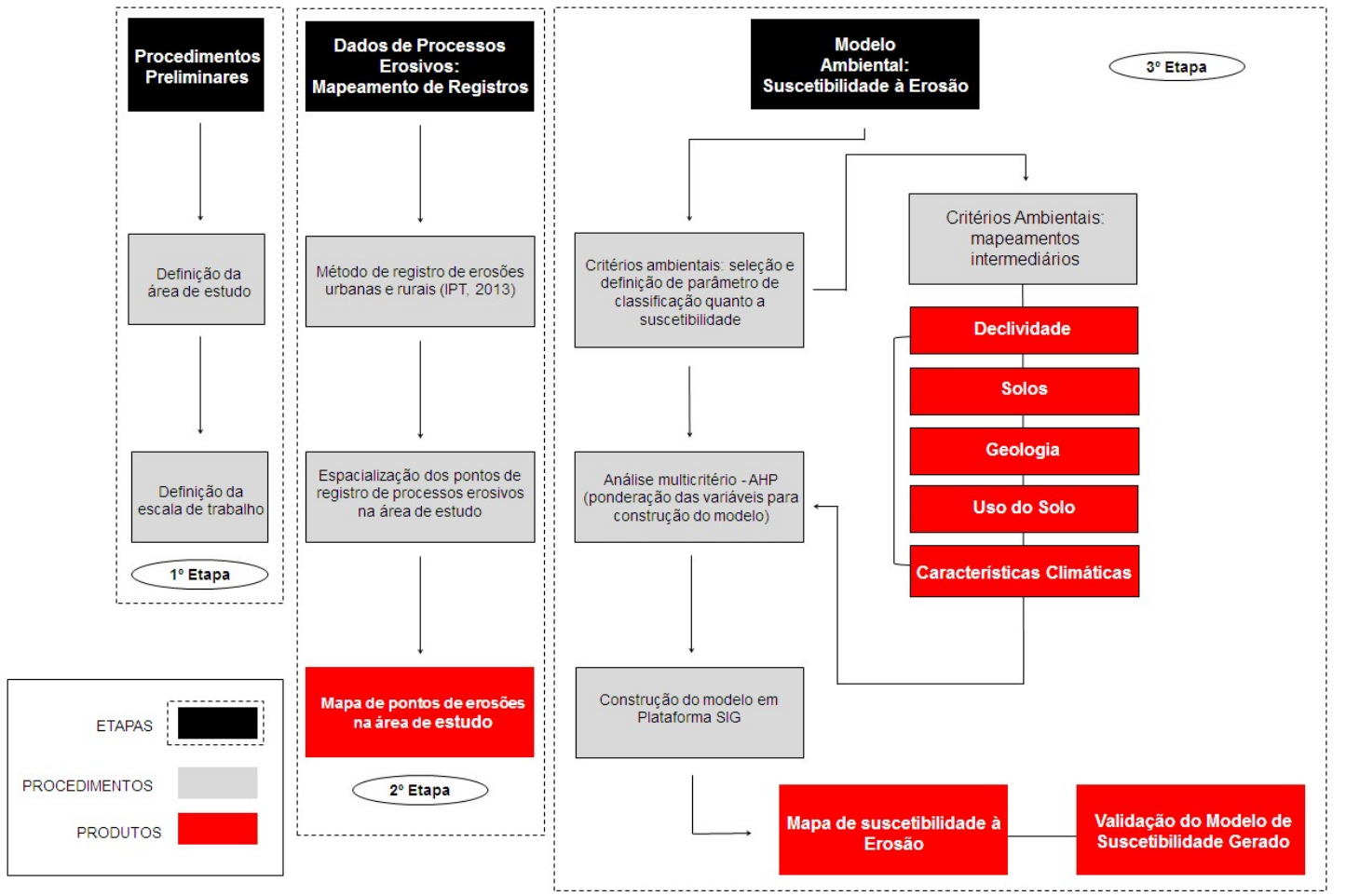

Figura 1 - Fluxograma metodológico das etapas envolvidas.

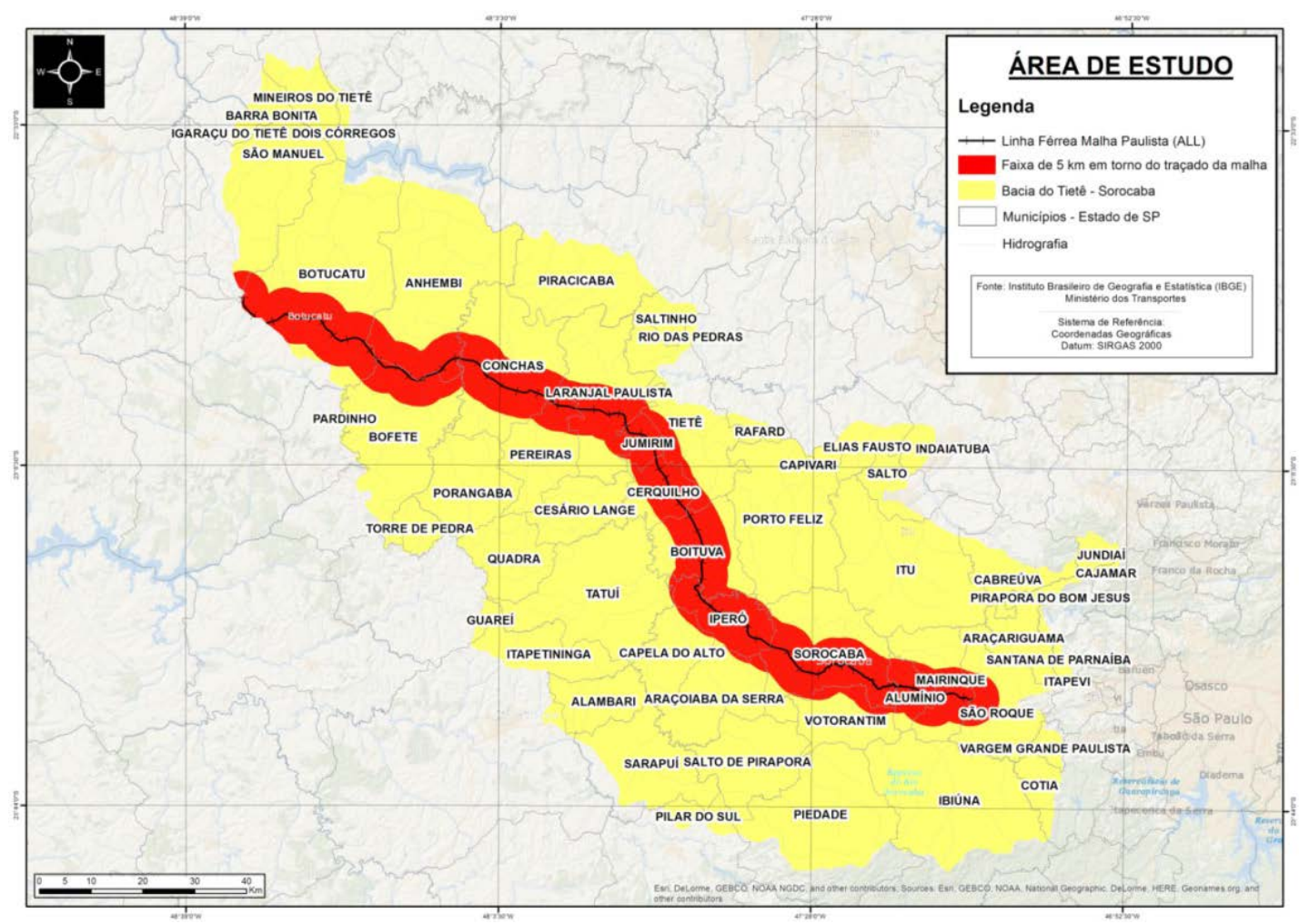

Figura 2 - Mapa da área de estudo. 
Priorizou-se o uso e fornecimento de mapeamentos das variáveis ambientais na escala entre 1:50.000 e 1:150.000, classificadas por Ross (1994; 1995) como sendo escalas aplicadas a estudos regionais. Para os dados de pedologia e características topográficas foram selecionadas técnicas de geoprocessamento e sensoriamento remoto conhecidas na literatura da ciência da informação geográfica e cartografia digital, de forma a alcançar a menor escala entre o intervalo proposto.

Especialmente para o tema de uso e cobertura do solo, a escala de mapeamento do tema foi de 1:150.000, justificada pelas tipologias classificadas na imagem (compatíveis com imagens LANDSAT-5-TM) e pela disponibilidade de imagens gratuitas na área de estudo. Nos casos em que não foi possível atingir o intervalo de escalas propostas, como é o caso dos dados de geologia e pluviometria, foram consideradas as questões levantadas nos trabalhos desenvolvidos por Fagundes (2013) e Spörl \& Ross (2004). Fagundes (2013), especialmente, afirma que, frente à problemática da disponibilidade de dados em escalas diversas para a aplicação de modelos ambientais de suscetibilidade a erosão, os mapeamentos finais (e também os objetivos específicos relacionados à questão da escala) devem admitir a limitação dos produtos gerados e a necessidade de checagem, em campo, para verificação da base cartográfica gerada.

\section{Etapa 2: Mapeamento de registros e} espacialização dos dados

A base de dados de registro de processos erosivos da área de estudo foi obtida a partir de um projeto realizado pelo Instituto de Pesquisa Tecnológica do Estado de São Paulo (IPT, 2013), responsável por mapear todos os registros de erosões lineares existentes no Estado de São Paulo. Especificamente para a área de análise foram detectados 833 processos erosivos, classificados entre ravinas e boçorocas urbanas e rurais.

O método de registro dos processos baseou-se em: a. identificação dos processos erosivos a partir das imagens orbitais em limites administrativos urbanos; b. elaboração de fichas de cadastro; c. visitas de campo; d. compilação dos dados obtidos e comparação dos resultados.

Através das informações cedidas de coordenadas coletadas por GPS ou via imagens de satélite georreferenciadas utilizadas no registro dos processos, os dados foram inseridos em ambiente SIG (ARCGIS/ARCMAP 10.2.1 $\operatorname{ArcMap}^{\mathrm{TM}}$ ) no sistema de referência Lat/Long SIRGAS 2000.

\section{Etapa 3: Modelo ambiental: suscetibilidade à erosão}

A seleção das variáveis utilizadas para compor o modelo gerado, bem como a definição dos parâmetros de classificação quanto à suscetibilidade ao desenvolvimento de processos erosivos utilizou-se do método desenvolvido por Crepani et. al. (2001). A figura 3 resume o procedimento de classificação das categorias morfodinâmicas referente aos níveis de suscetibilidade do terreno ao desenvolvimento de processos erosivos.

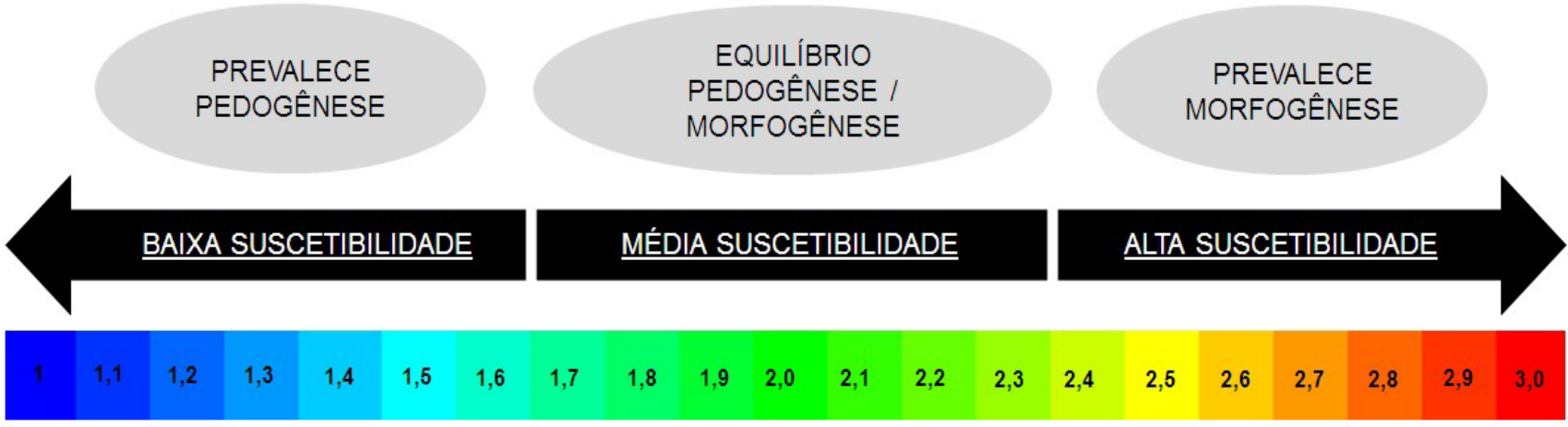

Figura 3 - Categorias morfodinâmicas referente aos níveis de suscetibilidade do terreno ao desenvolvimento de processos erosivos (alta, média e baixa suscetibilidade). Fonte: Adaptado de Crepani et al. (2001).

Os subitens que seguem descrevem os critérios de classificação adotados para análise dos agentes desencadeadores de processos erosivos considerados na metodologia utilizada: Geologia, Características do Relevo (dissecação pela drenagem e declividade), Pedologia, Uso da Terra, e Clima (intensidade pluviométrica).

\section{Geologia}

A contribuição da geologia para a análise e definição da categoria morfodinâmica do terreno compreende as informações relativas à história da evolução geológica do ambiente onde a unidade 
se encontra e ao grau de coesão das rochas que o compõe. Para mapeamento das propriedades geológicas, as cartas temáticas do Projeto "Mapeamento Geológico Estadual”, do Serviço Geológico do Brasil (CPRM) referentes à área de estudo foram georreferenciadas e vetorizadas em arquivos de polígonos (shapefille). Cabe dizer que, para o tema Geologia, não foi gerado o mapeamento no intervalo de escalas proposto (1:50.000 a 1:150.000) devido à falta de informações suficientes para o detalhamento das unidades geológicas encontradas. A base de dados utilizada foi originalmente mapeada na escala de 1:750.000 para todo o estado de São Paulo e dispõe de informações sobre tipos de rocha (litologia, classe de rocha e subclasse), unidades geológicas, era geológica e hierarquia (grupo, formação).

\section{Características do Relevo}

Para estabelecer os valores da escala de suscetibilidade com relação às características do relevo foram analisados os índices morfométricos do terreno referentes à dissecação do relevo pela drenagem e à declividade.

Foram utilizadas informações referentes à rede de drenagem, pontos cotados de altimetria e curvas de nível oriundos de cartas de mapeamentos sistemáticos do Instituto Brasileiro de Geografia e Estatística (IBGE), Instituto Geográfico Geológico (IGG) e Departamento de Serviços Geográficos do Exército, na escala 1:50.000 (projeto GISAT). Para geração do mapa de declividade, foi gerado, a partir das curvas de níveis, pontos cotados e rede de drenagem, um

$$
\text { indice de dissecação do relevo }=\frac{\text { comprimento da rede de drenagem }(m)}{\text { área }\left(m^{2}\right)}
$$

\section{Solos}

Na análise da suscetibilidade dos tipos de solo, considera-se o seu grau de maturidade, produto direto do balanço morfogênese/pedogênese. O processo de mapeamento de solos da área de estudo baseou-se na proposta de Hermuche et al. (2002) que discute a geração de produtos cartográficos referente à pedologia baseados na análise estatística da distribuição do histograma de frequência de atributos topográficos. O histograma de frequência dos dados de declividade e hipsometria indicam onde estão as zonas de transições entre as principais classes de solos. Dessa forma, esse tipo de análise pode indicar a divisão das unidades de solo no terreno tendo como referência padrões morfométricos
MDT (Modelo Digital de Terreno), com resolução de $50 \mathrm{~m}^{2}$ (grid de $25 \times 25 \mathrm{~m}$ ) no programa ARCGIS 10.2.2. Segundo Rabaco (2005), esse módulo Topo to Raster possui como principais vantagens a coerência nas análises hidrológicas e a continuidade da superfície, ausente nos demais métodos (ex. krigagem), resultando em uma estrutura de drenagem conectada e produzindo alta acurácia na superfície.

Quanto à dissecação do relevo, segundo Crepani et al. (2001) e Florenzano (2005), a intensidade de dissecação pela drenagem pode ser obtida através da densidade. Para a pesquisa, foram extraídos índices de densidade de drenagem por $\mathrm{m}^{2}$ através do somatório dos comprimentos da rede de drenagem (em metros) por unidade de área $\left(\mathrm{m}^{2}\right)$. Baseado em Arnesen et. al. (2009) e Florenzano (2005), a unidade de área é definida a partir da obtenção do mapeamento de compartimentos geomorfológicos da área de estudo. Nesse caso, foi utilizado a base vetorial digital disponibilizada pela CPRM referente ao projeto de "Mapeamento Estadual de Geodiversidade”, na escala de 1:75 0.000 e a mesma base vetorial digital referente à drenagem utilizada para obtenção do Modelo Digital de Terreno. Para o procedimento de obtenção do índice, o arquivo de polígonos referente às unidades de área dos diversos compartimentos geomorfológicos existentes foi convertido em arquivo matricial (raster) e cruzado com o mapeamento de rede de drenagem. $O$ índice de dissecação para cada unidade de área é definido pela Equação 1:

(Hermuche et al., 2002).

Para análise dos atributos topográficos e geração dos histogramas de frequência foi utilizado o Modelo Digital de Terreno gerado anteriormente. Um mapeamento pedológico na escala 1:500.000 fornecido pela Escola Superior de Agricultura (ESALQ-USP) para o Estado de São Paulo também foi utilizado para comparação dos resultados do produto gerado para a área de estudo.

\section{Clima}

Particularmente no caso das análises de características climáticas, a geração de dados referentes ao regime pluviométrico através do uso de técnicas de geoestatística é bastante comum. Para geração do mapeamento de comportamento 
pluviométrico da área de estudo foram aplicadas técnicas de interpolação através da krigagem ordinária. A coleta da série histórica dos postos disponíveis para consulta foi feita através do banco de dados pluviométricos do Estado de São Paulo disponibilizados em conjunto pela ANA e DAEE (SIGRH - Estado de São Paulo). Os dados foram organizados em planilhas e a determinação dos valores para interpolação de pontos nãoamostrados foi o resultado da divisão das médias mensais referentes aos registros dos anos de funcionamento de cada posto coletado.

Todos os processos envolvidos na geração do mapeamento de comportamento pluviométrico, no ajuste e análise dos variogramas foram processados no software Geovisual ${ }^{\mathrm{TM}}$, desenvolvido pelo Instituto de Geociências da Universidade de São Paulo.

\section{Uso e cobertura do solo}

Para o mapeamento das classes de uso e cobertura do solo foram utilizadas imagens cedidas pela Secretaria do Meio Ambiente, do Governo do Estado de São Paulo (SMA - SP), por meio da Coordenadoria de Planejamento Ambiental (CPLA), responsável pela disponibilização de cenas de imagens do satélite LANDSAT - TM - 5 do ano de 2010. A escala de mapeamento foi de 1:150.000. Justifica-se a geração do produto cartográfico na escala proposta, por conta das tipologias definidas no processo de classificação da imagem (corpos d'água, áreas úmidas, cobertura arbórea, área construída, áreas agropastoris e solo exposto) e a disponibilidade de cenas gratuitas que recobrem a totalidade da área de estudo.

As áreas de interesse apresentam grandes extensões territoriais (acima de $30 \mathrm{~m}$ ), sendo facilmente identificadas no tipo de imagem selecionada.

Quanto ao processo de classificação, as técnicas de processamento digital das imagens incluíram as etapas de composição colorida, segmentação por crescimento de regiões, treinamento, classificação e análise da classificação.

\section{Análise multicritério - AHP (Analytic Hierarchy process)}

Os métodos de análises multicritérios são procedimentos metodológicos de cruzamento de informações amplamente aceitos nas análises espaciais com SIG. Para o presente trabalho, adotou-se como procedimento a aplicação da técnica Análise Hierárquica de Pesos (AHP).

Esse processo resulta uma matriz de comparação para a avaliação de cada variável analisada baseia-se na definição do grau de pertinência de cada plano de informação e de cada um de seus atributos para a construção do resultado final.

A definição dos parâmetros de ponderação das variáveis foi analisada por especialistas do Instituto de Pesquisa Tecnológica - IPT do Laboratório de Riscos Ambientais (LARA), responsáveis pelo desenvolvimento de estudos relacionados ao controle de erosão.

Todo o processo de julgamento citado foi modelado no software Microsoft Excel ${ }^{\mathrm{TM}}$, utilizando o princípio do AHP para gerar os percentuais das relevâncias para os dados de saídas manuseados para a construção da expressão algébrica do processo de mapeamento. O julgamento par a par das variáveis e o índice resultante da comparação serão apresentados no capítulo de resultados.

\section{Construção do modelo em plataforma SIG}

O processo de mapeamento utiliza-se de toda preparação de dados das etapas anteriores e da geração de produtos cartográficos através de operações espaciais de álgebra de mapas.

O conceito de álgebra de mapas ou álgebra de campos pode ser visto como uma extensão da álgebra tradicional, com um conjunto de operadores e algoritmos matemáticos, em que as variáveis manipuladas são campos geográficos (Berry, 1993).

No SIG foi utilizada a ferramenta weigheted overlay que constrói e executa uma única expressão de álgebra de mapas composta pelos valores fornecidos das ponderações resultantes da aplicação do método AHP e dos critérios de classificação adotados pela metodologia de Crepani et al. (2001) quanto aos níveis de suscetibilidade das variáveis analisadas. A figura 4 resume o procedimento de construção do modelo no SIG.

\section{Mapeamentos intermediários: variáveis ambientais Geologia}

O mapeamento geológico da área de estudo evidenciou a presença de 21 unidades geológicas formadas por mais de 40 tipos de rochas. Mais de $70 \%$ da área de estudo analisada apresenta unidades geológicas e tipos litológicos classificados como de alta suscetibilidade à erosão (argilitos, folhelhos, depósitos de cascalhos e arenito - Figura 5), originados de rochas sedimentares, as mais suscetíveis na escala de 
classificação utilizada.

Com classificações de suscetibilidade à erosão acima de 2,8, as formações Pirambóia e
Itararé são as unidades que ocupam maiores proporções de área e concentram-se entre os trechos de Sorocaba e Botucatu.

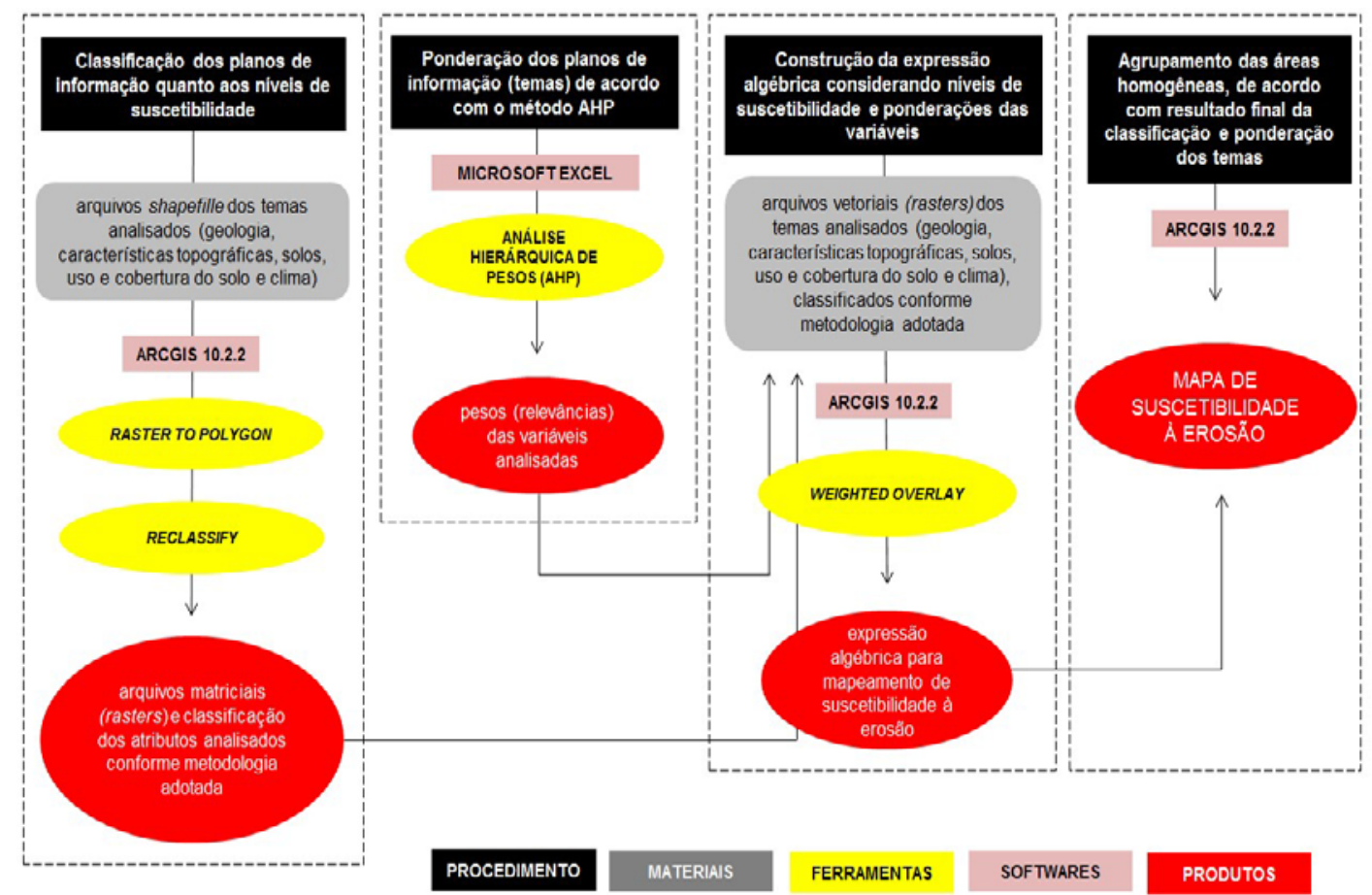

Figura 4 - Procedimentos para construção do modelo de suscetibilidade à erosão no SIG.

\section{RESULTADOS}

Características topográficas: declividade e dissecação do relevo pela drenagem

A área de análise presenta maiores percentuais de áreas com valores de declividade com valores de até $2^{\circ}$ e acima de $2^{\circ}$ até $4,6^{\circ}$, sendo uniforme a distribuição desses intervalos por toda área de análise. De modo geral, declividades de até $6^{\circ}$ são classificadas como intervalos de terrenos propensos a níveis com fragilidade ambiental muito baixa (Ross, 1995; Crepani et al., 2001; Salomão, 1999).

Os valores registrados, que variam de $2^{\circ}$ até $27^{\circ}$ apresentam distribuições similares quanto o percentual de área contida em cada intervalo. Os trechos com maiores declividades estão concentrados nos extremos da linha férrea, nos municípios de Botucatu, Mairinque e Alumínio. De acordo com Ross (2000), classes de declividade acima $15^{\circ}$ estão propensas às classificações de alta a muito alta fragilidade ambiental e suscetibilidade à erosão.

Quanto ao índice de dissecação do relevo pela drenagem, mais de $90 \%$ da área de estudo é formada basicamente por domínios de colinas amplas e suaves, colinas dissecadas, morros e serras baixas.

Esses domínios concentram um total de mais de 2.386 metros de rios, igarapés, córregos e riachos, classificados como permanentes ou intermitentes. No total, a área de estudo apresenta um índice de dissecação pela drenagem, médio, de 0,00428 (baixa suscetibilidade).

De acordo com a classificação adotada, os compartimentos geomorfológicos analisados apresentam baixos índices de dissecação do relevo pela drenagem, com valores variando entre 0,000 e 3,272 (baixa suscetibilidade à erosão).

Os domínios que apresentaram maiores índices de dissecação do relevo pela drenagem foram os de morros e serras baixas. Tais domínios representam mais de 30\% da área total de análise e estão concentrados no traçado da linha que liga os municípios de Alumínio à Iperó. Os mapas seguem ilustrados pelas figuras 6 e 7 .

\section{Solo}

Para aplicação da técnica de mapeamento de solo proposta foi necessário, de antemão, uma verificação de tipos de solos existentes na área de estudo, identificadas através de mapeamentos secundários disponíveis. Tal verificação permitiu identificar o comportamento das características topográficas das classes de tipos de solo existentes na região. 


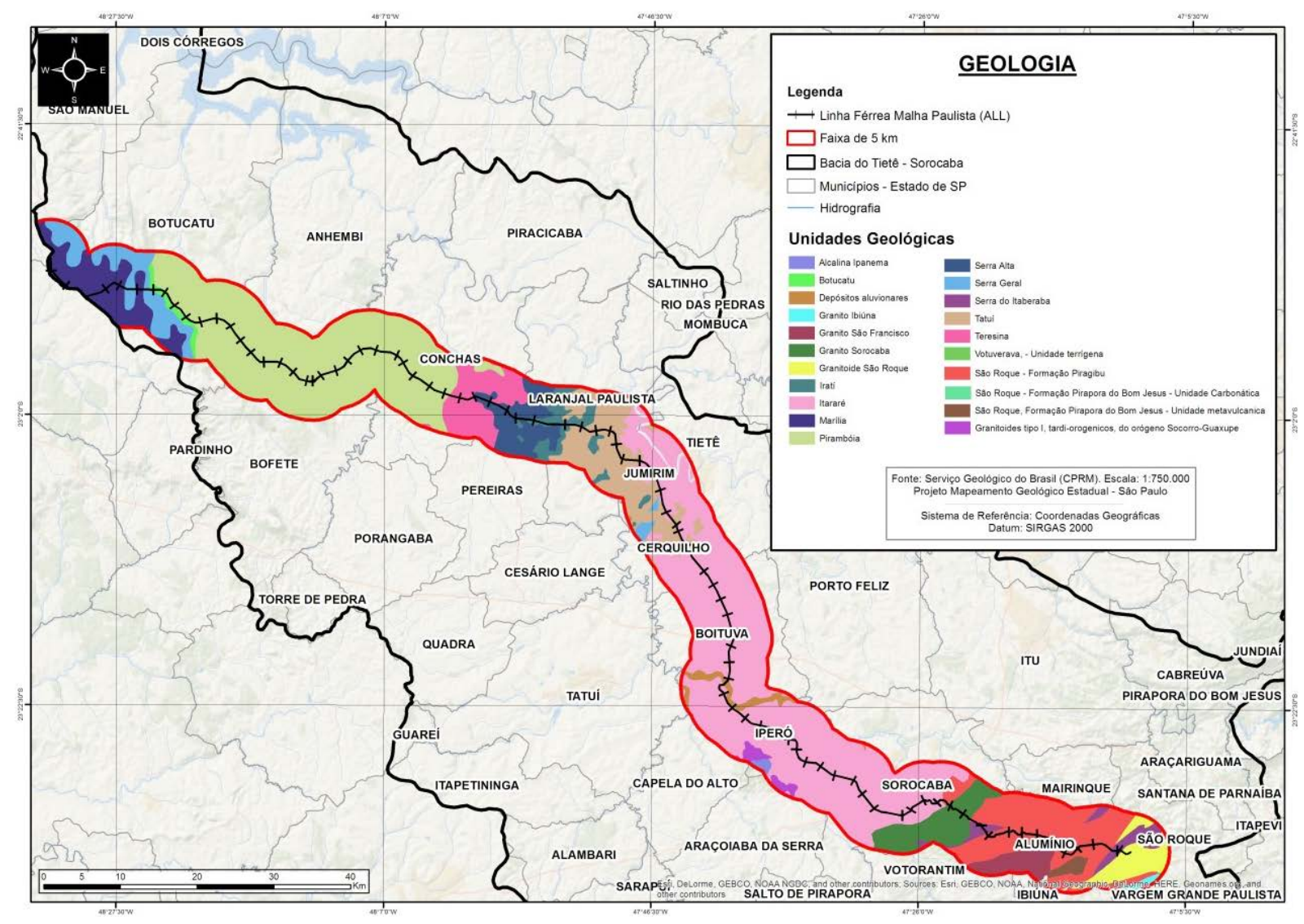

Figura 5 - Mapa de Geologia.

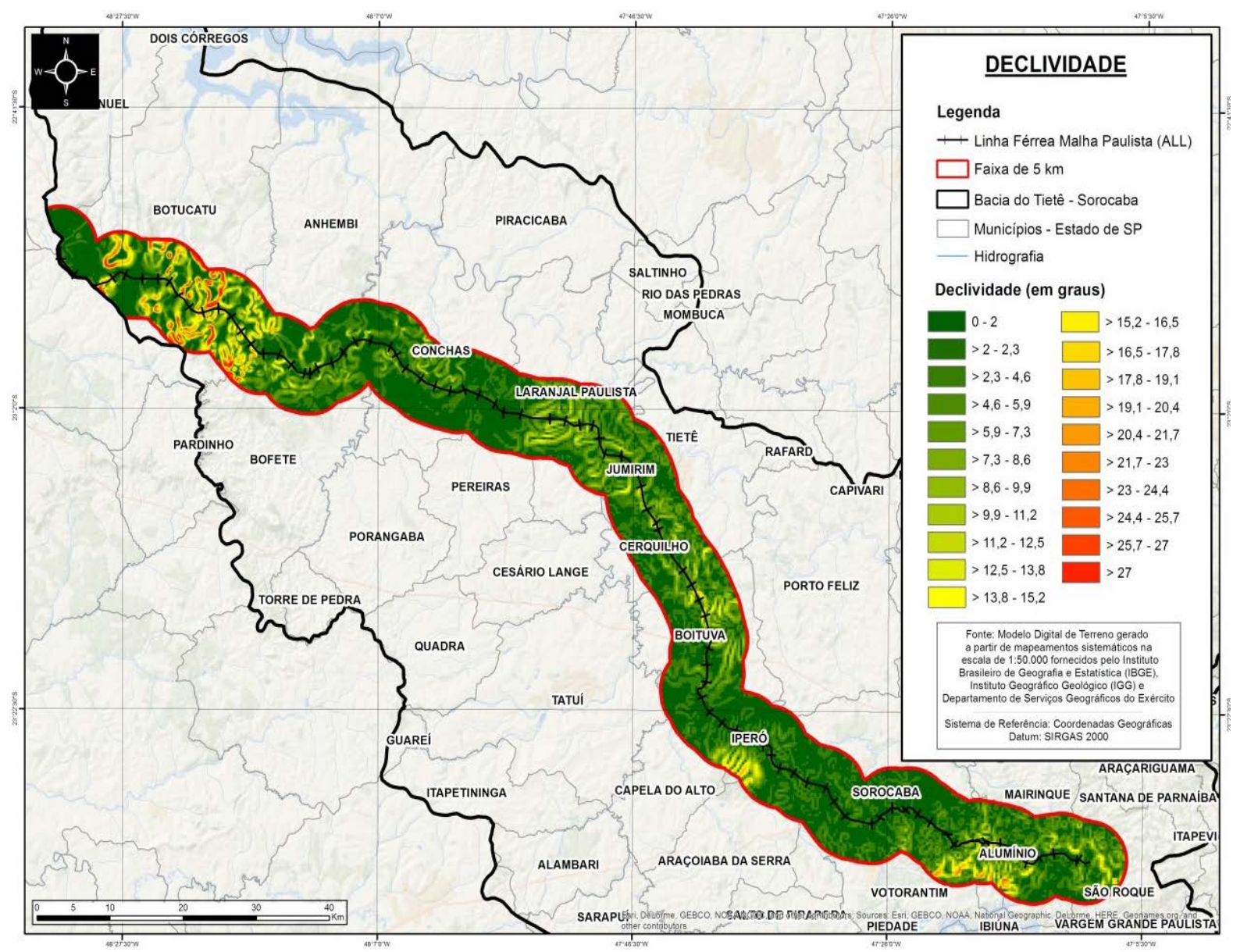

Figura 6 - Mapa de Declividade. 
A partir do cruzamento do mapeamento pedológico com os mapeamentos de declividade e hipsometria da área de estudo foi possível traçar o perfil de distribuição das diferentes tipologias de solo e suas características topográficas. Os histogramas de declividade e hipsometria gerados auxiliaram na análise da diferenciação entre uma classe e outra, indicando zonas de transição através da distribuição de frequências.

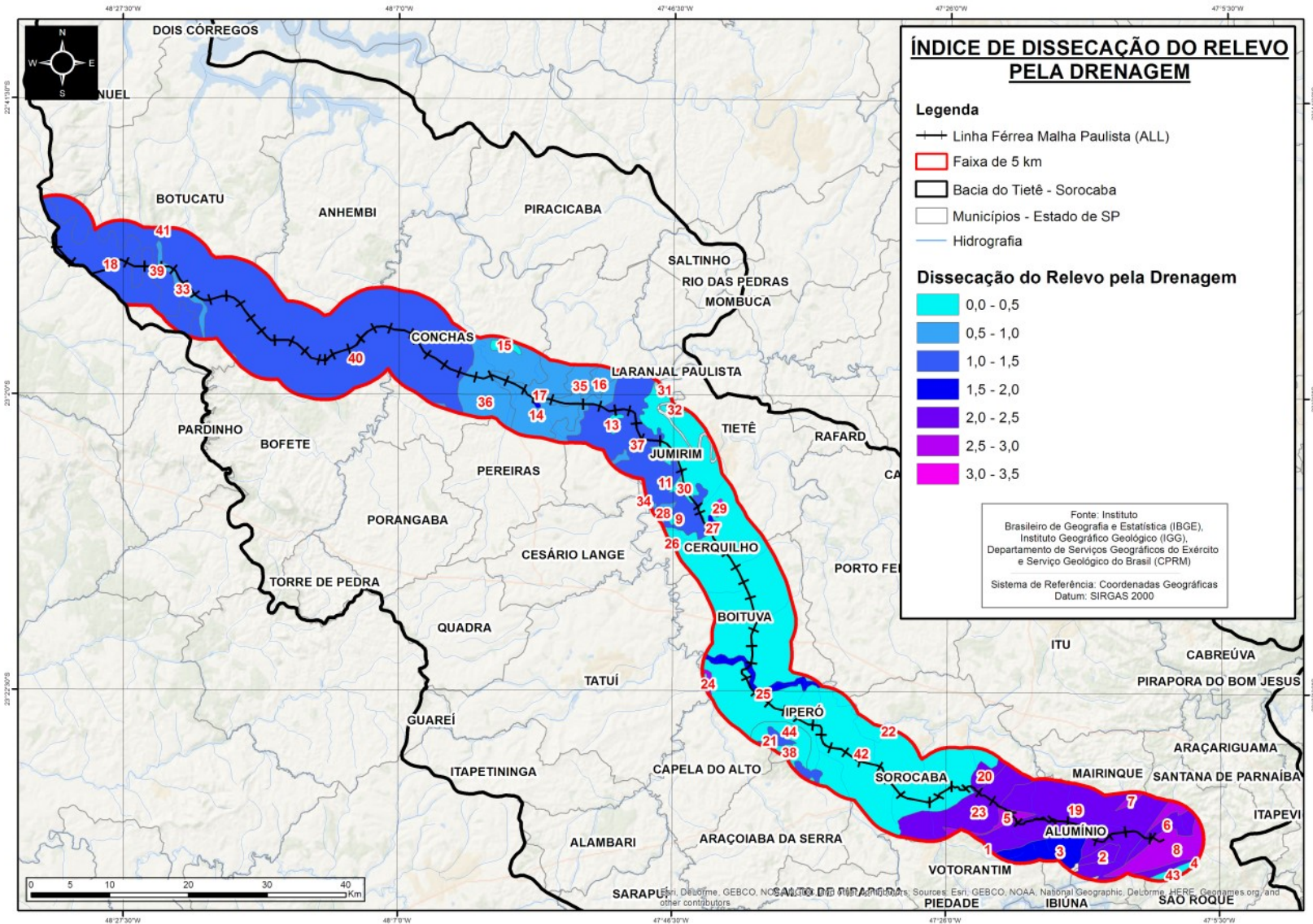

Figura 7 - Mapa de Dissecação do Relevo pela Drenagem.

Sobre os tipos de solos encontrados, podese dizer que os Latossolos são solos profundos, bem drenados, com textura média ou mais fina e pequena variação de argila entre os horizontes, o que permite uma maior infiltração d’água no sentido vertical e, consequentemente, apresenta menor densidade de drenagem superficial. Geralmente ocorrem em relevos planos ou suavemente ondulados, com baixa declividade, onde é menor o grau de erosão.

Já os Argissolos também são solos profundos, porém com maior teor de argila no horizonte $\mathrm{B}$, fazendo com que a infiltração d’água seja mais lenta, aumentando a drenagem superficial, bem como sua capacidade erosiva. Geralmente ocorrem em relevos ondulados ou fortemente ondulados, com declividade um pouco mais acentuada.

Por fim, os Nitosolos formam-se sobre rochas básicas e ocupam as porções média e inferior de encostas onduladas até fortemente onduladas. Apresentam riscos de erosão se estiverem localizados em relevos ondulados.

Em vista de suas características, à exceção do relevo, esses solos têm aptidão boa para lavouras e demais usos agropastoris.

A definição dos parâmetros estatísticos das classes de solos identificadas está definida na tabela 1 .

Já a tabela 2 traz a comparação entre os dois mapeamentos de solos da região e a classificação dos tipos de solos segundo a metodologia adotada de suscetibilidade à erosão.

\section{Clima}

O mapeamento do comportamento pluviométrico e a geração do variograma para interpolação dos dados não-amostrados foram baseados nos valores coletados, referente aos postos pluviométricos consultados, resultantes da divisão entre o total pluviométrico anual médio pela média mensal dos anos de funcionamento. 
Tabela 1 - Definição dos parâmetros estatísticos das classes de solos identificadas.

\begin{tabular}{l|c|c|c|c}
\hline \multicolumn{5}{c}{ TIPOS DE SOLOS - PARÂMETROS ESTATISTICOS - DECLIVIDADE } \\
\hline \multicolumn{1}{|c|}{ Tipo de Solo } & Menor Valor & Maior Valor & Média & Desvio Padrão \\
\hline Argissolo & 1 & 39 & 6 & 5,93 \\
Latossolo & 1 & 52 & 7 & 6,28 \\
Nitossolo & 1 & 33 & 9 & 5,88
\end{tabular}

\begin{tabular}{l|c|c|c|c}
\hline \multicolumn{5}{c}{ TIPOS DE SOLOS - PARÂMETROS ESTATICOS - HIPSOMETRIA } \\
\hline \multicolumn{1}{|c|}{ Tipo de Solo } & Menor Valor & Maior Valor & Média & Desvio Padrão \\
\hline Argissolo & 399 & 1099 & 650 & 139,65 \\
Latossolo & 151 & 946 & 626 & 140,251 \\
Nitossolo & 492 & 916 & 738 & 102,92
\end{tabular}

Tabela 2 - Tipos de solos mapeados (mapeamento ESALQ e mapeamento gerado) - Área equivalente e classificação de suscetibilidade à erosão.

\begin{tabular}{|c|c|c|}
\hline \multicolumn{3}{|c|}{ Mapeamento gerado (metodologia HERMUCHE,2002) } \\
\hline Tipo de Solo & Área $\left(\mathrm{km}^{2}\right)$ & Classificação \\
\hline Latossolo & 520 & 1,0 \\
\hline Argissolo & 1.112 & 2,0 \\
\hline Nitossolo & 279 & 2,0 \\
\hline Total & $3.822,00$ & \\
\hline \multicolumn{3}{|c|}{ Mapeamento ESALQ - 1:500.000 } \\
\hline Tipo de Solo & Área $\left(\mathrm{km}^{2}\right)$ & Classificação \\
\hline Latossolo & 521 & 1,0 \\
\hline Argissolo & 1.343 & 2,0 \\
\hline Nitossolo & 47 & 2,0 \\
\hline Total & $3.822,00$ & \\
\hline
\end{tabular}

A figura 8 é o resultado do cálculo do variograma experimental calculado. Os parâmetros utilizados, como tamanho do passo, campo geométrico e número de passos estão discriminados na mesma figura. Já a figura 9 apresenta o variograma teórico, originado do processo de ajuste do variograma experimental. Para o melhor ajuste alcançado, os valores de patamar, efeito pepita e alcance também seguem especificados.

Os resultados mostraram uma variação de médias anuais de volumes de chuva que vão de $101 \mathrm{~mm}$ a $123 \mathrm{~mm}$. Os valores mais altos são observados nas áreas dos municípios de Mairinque e Botucatu (nos extremos da linha férrea). Na relação dos valores de pluviometria com outras particularidades ambientais, notouse uma importante correlação dos maiores valores encontrados de pluviometria com os de índices de dissecação do relevo pela drenagem e declividade. Embora o intervalo de médias mensais encontrado na região varie entre 100 à $120 \mathrm{~mm} / \mathrm{mês}$, toda a área analisada foi classificada como de baixa suscetibilidade à erosão no que diz respeito às médias pluviométricas.

O mapeamento final do comportamento pluviométrico é apresentado na figura 10 .

\section{Uso e cobertura do solo}

O mapeamento de uso e cobertura da área (Figura 11) evidenciou aproximadamente 60\% da área total de estudo como pertencentes a áreas agropastoris, definidas previamente como sendo áreas de pasto melhoradas ou cultivadas destinadas ao pastoreio. Também se encontram inseridas nesta categoria as culturas temporárias, semi-perenes e perenes. A tabela 3 descreve o percentual de cada tipo de uso definido e mapeado. Através dos dados, podemos observar que aproximadamente $70 \%$ da área de estudo estão inseridas em categorias de uso e cobertura classificadas como de alta suscetibilidade à erosão. As classes de baixa suscetibilidade (corpos d'água, áreas úmidas e cobertura arbórea) representam apenas 25\% da área considerada. 


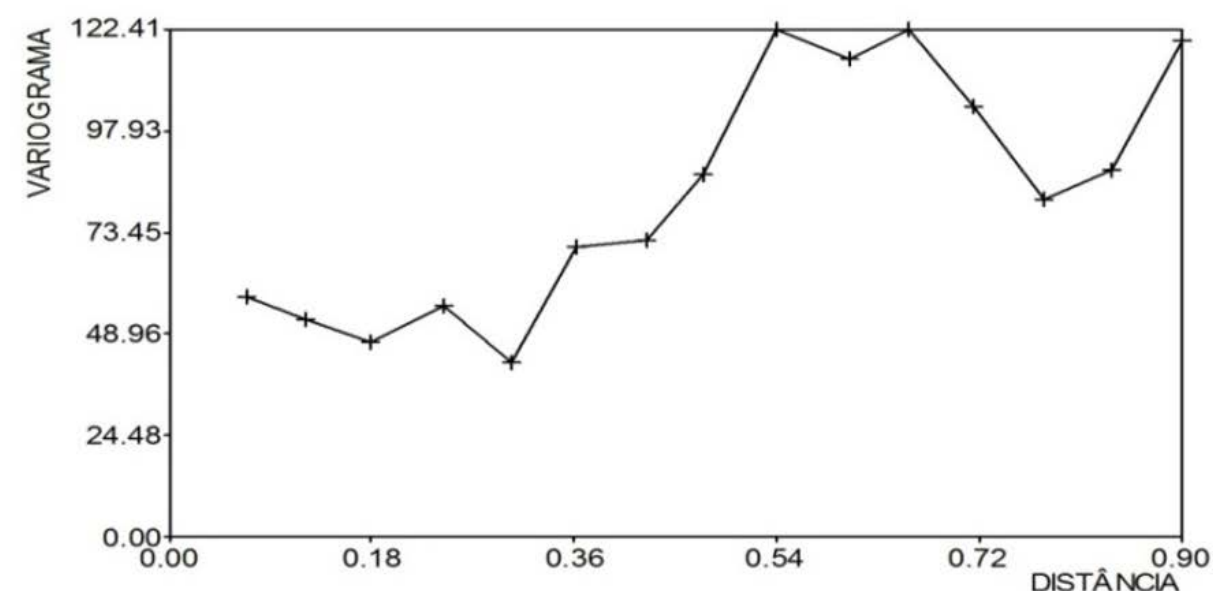

PARAMETERS FOR EXPERIMENTAL SEMIVARIOGRAMS
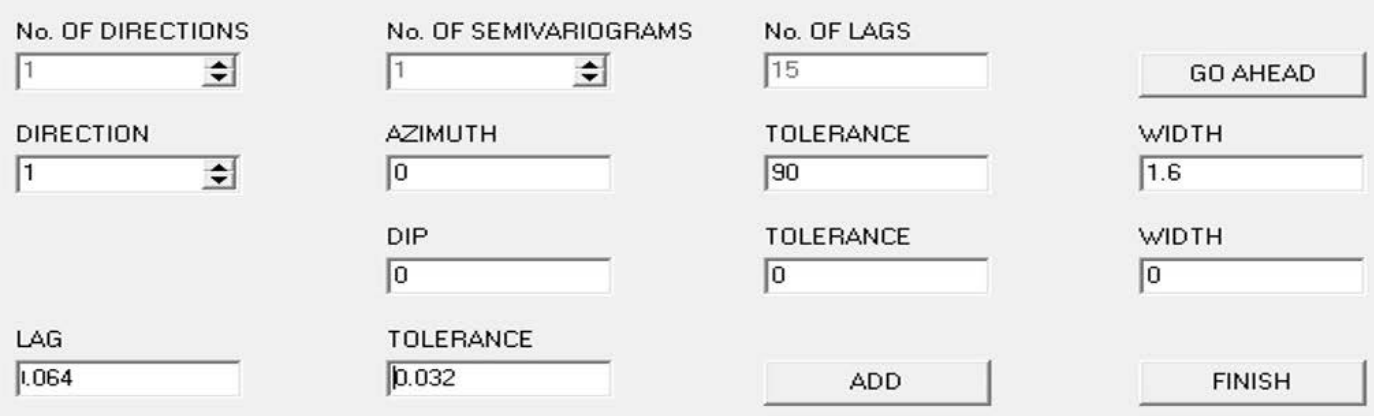

Figura 8 - Variograma experimental e parâmetros utilizados. Fonte: Geovisual, 2015.
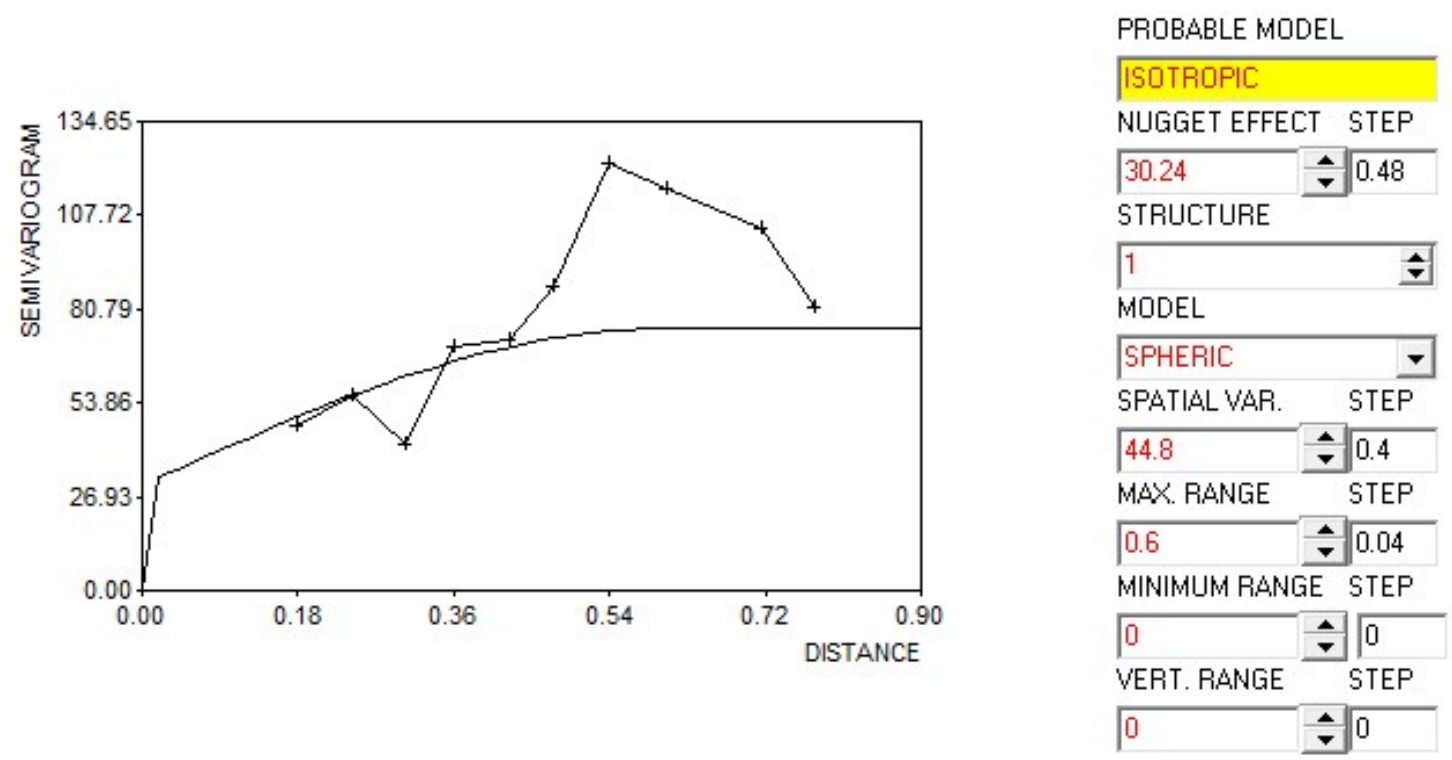

Figura 9 - Variograma teórico (linha de ajuste) e parâmetros utilizados. Fonte: Geovisual (2016).

Análise AHP - Ponderações estatísticas para geração do indicador de suscetibilidade

Para definição da ponderação final, todos os julgamentos par a par das variáveis foram analisados e foi considerada a nota média para cada caso. A figura 12 apresenta a matriz final de julgamento oriunda das avaliações dos especialistas. Já a figura 13 apresenta os resultados dos parâmetros de peso (relevância resultantes da análise multicritério) utilizados na equação aplicada ao processamento das bases cartográficas envolvidas e geração do mapeamento de suscetibilidade à erosão.

A variável de maior relevância para geração do mapeamento de suscetibilidade foi "Tipo de Solo" (45\%). 
A variável "Uso e Cobertura do Solo" apresentou importância relativa de $22 \%$ e "Pluviometria" de 15\%. Por fim, "Características Topográficas” (declividade e índice de dissecação do relevo) representam, cada, apenas $0,9 \%$ do peso.

Mapeamento de suscetibilidade à erosão e validação do modelo gerado

A figura 14 é o resultado do mapeamento final de suscetibilidade à erosão da área de estudo. Já a figura 15 são os processos erosivos registrados na área de estudo e utilizados para validação do modelo.

A metodologia aplicada e a ponderação realizada a partir do cruzamento das variáveis consideradas para mapeamento de suscetibilidade à erosão possibilitaram a identificação de áreas de baixa, média e alta suscetibilidade, com níveis variando de 1,5 a 2,7 na escala adotada.

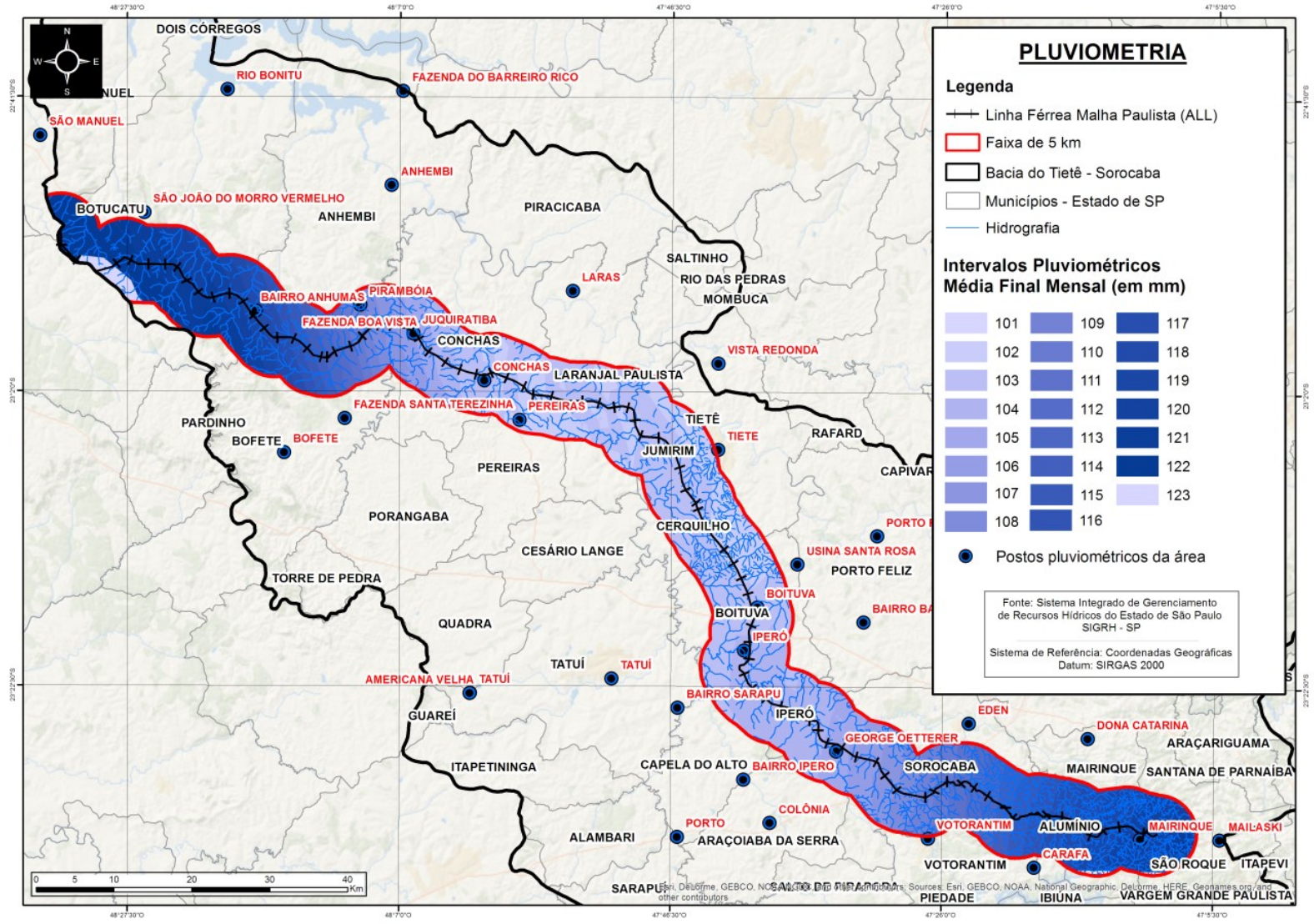

Figura 10 - Mapa de Pluviometria.

Tabela 3 - Classes de uso e cobertura do solo e classificação de suscetibilidade à erosão.

\begin{tabular}{c|c|c|c}
\hline Uso e Cobertura do Solo & Área & Área & Classificação \\
\hline Classe & $\mathbf{( \mathbf { K m } ^ { 2 } )}$ & $\mathbf{( \% )}$ & Suscetibilidade (CREPANI) \\
\hline Corpos d'água & 11,8010 & 0,6207 & \\
Áreas úmidas & 0,3628 & 0,0191 & \\
Cobertura arbórea & 451,2990 & 23,7360 & 1,5 \\
Área construída & 199,2460 & 10,4793 & 2,5 \\
Áreas agropastoris & $1.124,1760$ & 59,1259 & 2,7 \\
Solo exposto & 114,4400 & 6,0190 & 3,0 \\
\hline Total & $1.901,3248$ & &
\end{tabular}




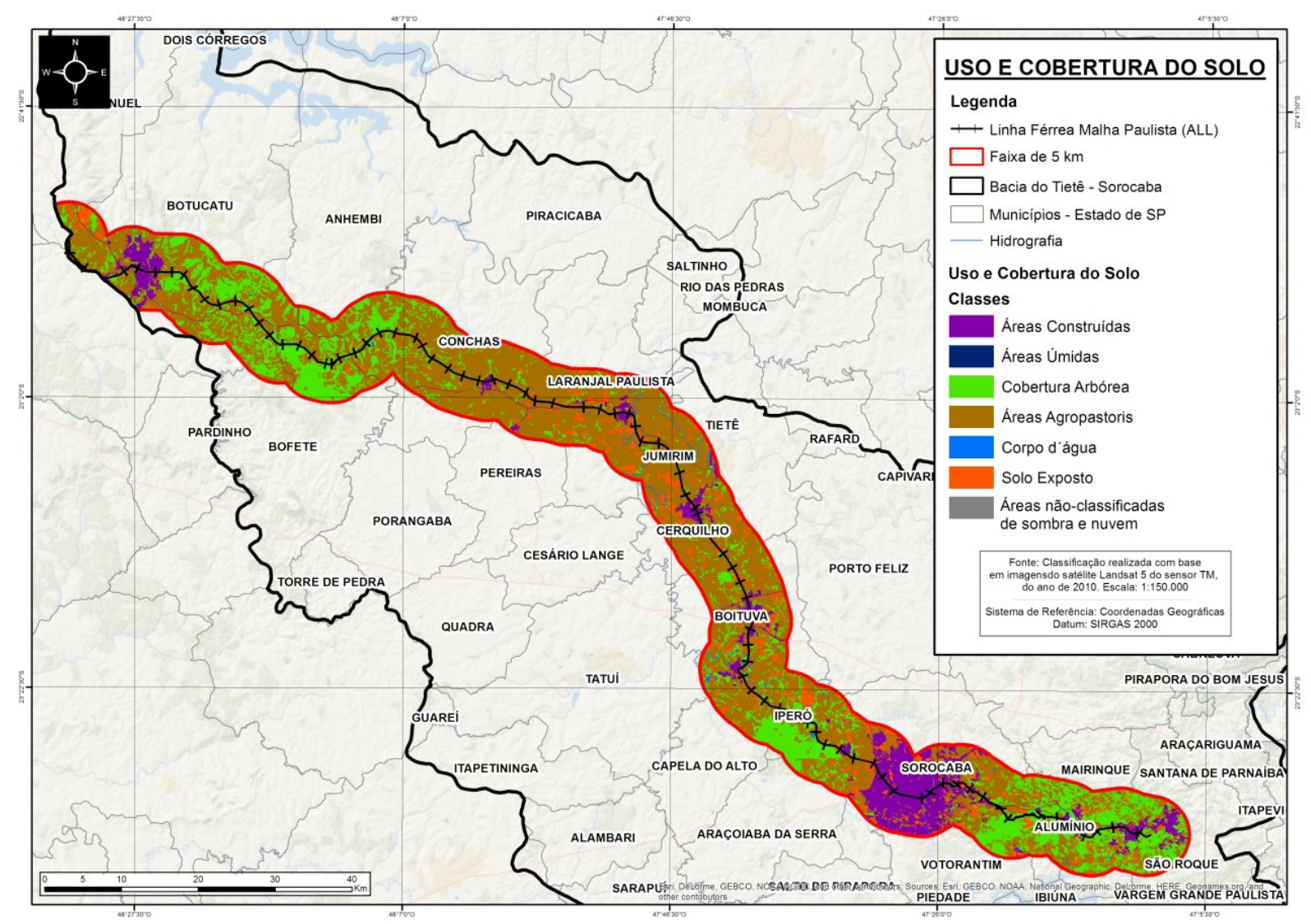

Figura 11 - Mapa de Uso e Cobertura do Solo

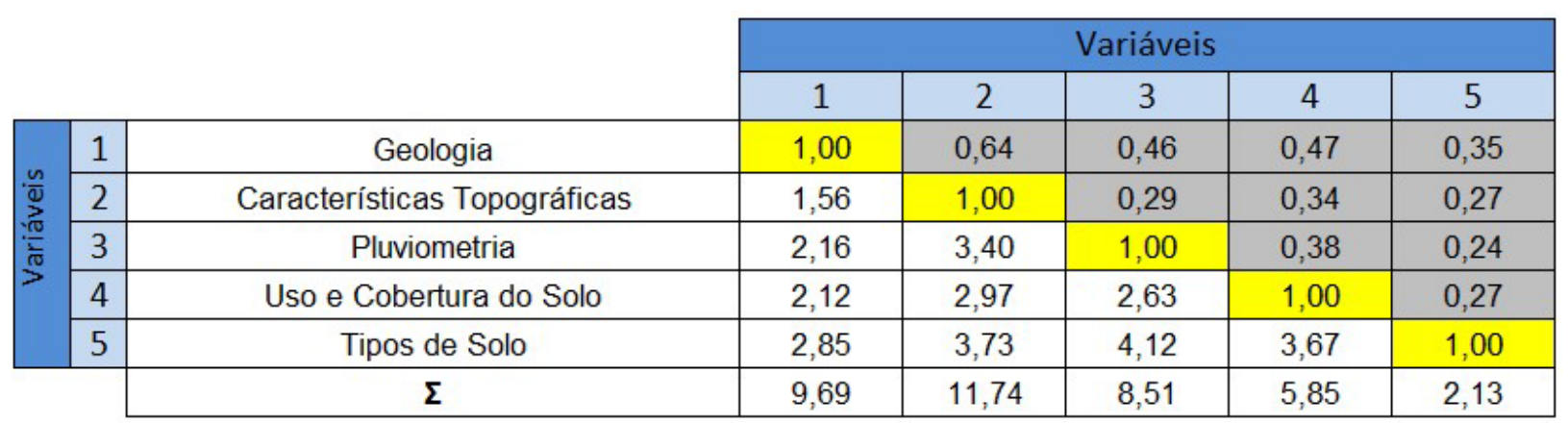

Figura 12 - Matriz final de julgamento oriunda das avaliações dos especialistas: média dos julgamentos.

\begin{tabular}{|c|c|c|}
\hline \multirow{5}{*}{$\mid \frac{\omega}{0}$} & 1 & Geologia \\
\hline & 2 & Características Topográficas \\
\hline & 3 & Pluviometria \\
\hline & 4 & Uso e Cobertura do Solo \\
\hline & 5 & Tipos de Solo \\
\hline & & $\Sigma$ \\
\hline
\end{tabular}

\begin{tabular}{|c|c|}
\hline Auto Vetor & $\begin{array}{c}\text { Auto Vetor } \\
\text { Normalizado }\end{array}$ \\
\hline 0,547048405 & $9 \%$ \\
\hline 0,529304686 & $9 \%$ \\
\hline 0,92494715 & $15 \%$ \\
\hline 1,351926501 & $22 \%$ \\
\hline 2,761839937 & $45 \%$ \\
\hline 6,115066678 & $100 \%$ \\
\hline
\end{tabular}

\begin{tabular}{|l|c|}
\hline$\lambda$-max & 5,429 \\
\hline IC & 0,107 \\
\hline Taxa de consistência & $10 \%$ \\
\hline
\end{tabular}

Figura 13 - Matriz final de julgamento oriunda das avaliações dos especialistas: média dos julgamentos. 


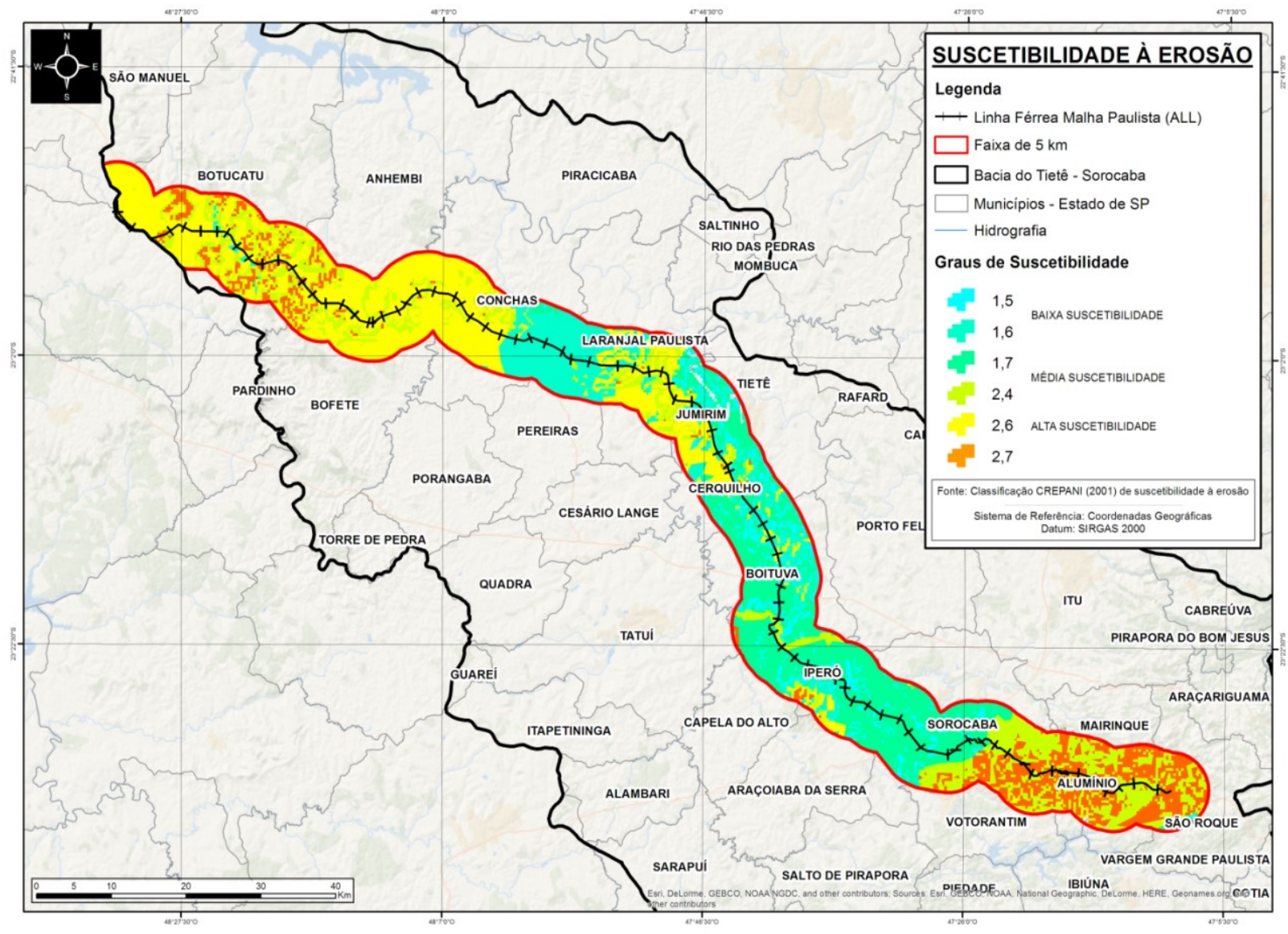

Figura 14 - Mapa de suscetibilidade à erosão.

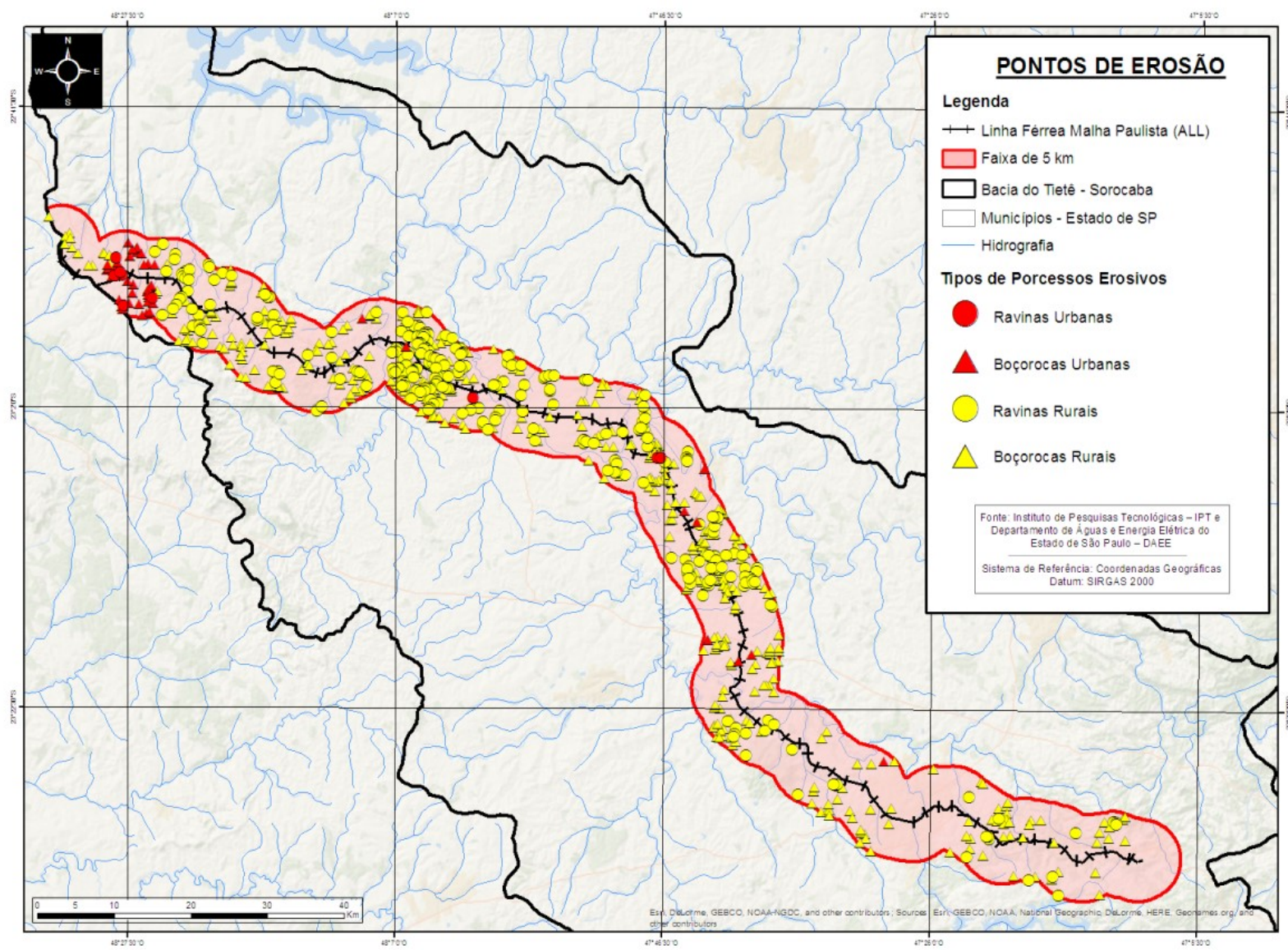

Figura 15 - Mapa de processos erosivos registrados. 
As áreas classificadas como de alta suscetibilidade à erosão (2,4, 2,6 e 2,7) representam aproximadamente $60 \%$ da área total da região de estudo e registram $65 \%$ dos processos erosivos mapeados.

Observa-se uma concentração dessas áreas em regiões localizadas nas extremidades da linha férrea.

Nessas regiões estão localizadas as maiores proporções de áreas urbanizadas, maiores índices de pluviometria, de graus de declividade e de tipos de solos mais suscetíveis ao desenvolvimento de processos erosivos.

As áreas de média suscetibilidade representam cerca de $23 \%$ da área de estudo e foram identificados $17 \%$ do total de registros de pontos de erosão pertencentes a essas áreas (regiões centrais do entorno da linha férrea, entre os municípios de Sorocaba e Cerquilho).

Já as áreas de baixa suscetibilidade à erosão representam apenas $17 \%$ da área de estudo. Nelas estão presentes $18 \%$ do total de registros de erosão. A concentração de índices de baixa suscetibilidade $(1,5$ e 1,6$)$ pode ser observada no trecho da linha que interliga as cidades de Laranjal Paulista e Conchas.

Uma forma de testar a validade do mapeamento gerado foi a aplicação do teste de correlação linear simples entre os índices encontrados e a quantidade de processos erosivos mapeados por classes de suscetibilidade.

$\mathrm{Na}$ análise dos dados resumidos na tabela 4, é possível observar que existe correlação positiva e direta entre o aumento do nível de suscetibilidade e o número de processos erosivos mapeados por classe.

Porém, há um decréscimo da quantidade de erosões encontradas na classe de maior suscetibilidade $(2,7-72$ processos erosivos mapeados).

Tabela 4 - Classificação final de suscetibilidade à erosão da área de estudo. Áreas de alta, média e baixa suscetibilidade à erosão - áreas proporcionais e quantidade de processos erosivos mapeados por classe.

\begin{tabular}{|c|c|c|c|c|c|}
\hline Classificação & Classificação & Área & Área & Processos Erosivos & Processos Erosivos \\
\hline Suscetibilidade (Graus) & Suscetibilidade (Classe) & $\left(\mathrm{km}^{2}\right)$ & $(\%)$ & RAVINAS / BOÇOROCAS (Quantidade) & RAVINAS / BOÇOROCAS (*) \\
\hline 1,5 & \multirow{2}{*}{ BAIXA } & 101,6022 & 5,344 & 60 & 7 \\
\hline 1,6 & & 236,1578 & 12,421 & 90 & 11 \\
\hline 1,7 & MÉDIA & 423,8796 & 22,294 & 140 & 17 \\
\hline 2,4 & \multirow{3}{*}{ ALTA } & 360,6492 & 18,968 & 158 & 19 \\
\hline 2,6 & & 530,0400 & 27,877 & 313 & 38 \\
\hline \multirow[t]{2}{*}{2,7} & & 215,9221 & 11,356 & 72 & 9 \\
\hline & & $1.901,3258$ & 100 & 833 & 100 \\
\hline
\end{tabular}

Uma possível explicação para isso é o fato das áreas classificadas como de maior suscetibilidade à erosão estarem localizadas em altitudes elevadas, dificultando o acesso pelo homem e até mesmo a possibilidade de ocupação do solo por áreas agropastoris, grandes responsáveis pelo desenvolvimento e aceleração da formação de processos erosivos.

Nessas regiões, que embora apresentem características ambientais que as definem como áreas altamente suscetíveis ao aparecimento de processos erosivos, a manutenção das áreas de florestas e cobertura vegetal (facilitada pela altitude) age diretamente no controle do aparecimento de erosões aceleradas por atividades antrópicas.

O gráfico da figura 16 ilustra a correlação existente entre os níveis de suscetibilidade mapeados e a quantidade de processos erosivos registrados por classe. A correlação substancial encontrada $(0,489)$ foi testada e resultou significante para um nível de 0,05 de significância. Baseado em Barbetta (2012), o resultado evidencia que existe correlação direta e positiva (moderada) entre o aumento de níveis de suscetibilidade mapeados e a quantidade de processos erosivos registrados por classe, já que o valor mínimo para ser considerada a correlação, para esse total de casos analisados, é de 0,398.

Caso a análise da correlação não considerasse as áreas classificadas na escala como sendo 2,7 (alta suscetibilidade, a maior encontrada no mapeamento de suscetibilidade) a correlação entre o aumento do nível de suscetibilidade e o número de processos erosivos mapeados por classe aumentaria para 0,879, indicando um aumento considerável entre as variáveis analisadas. 
Dessa forma, baseado na análise de associação entre quantidade de processos erosivos e aumento dos níveis de suscetibilidade do terreno, pode-se dizer que o modelo apresenta limitações relacionadas à modelagem de alguns níveis de suscetibilidade classificados como alta suscetibilidade à erosão.

Ainda fundamentado nos resultados na correlação, o modelo apresentou um $\mathrm{R}^{2}$ (Rquadrado) igual a 0,339 (Figura 17), sugerindo que, na amostra analisada, $34 \%$ da variação da quantidade de processos erosivos pode ser explicada por uma relação linear com o aumento de níveis de suscetibilidade do terreno. Os demais $66 \%$ são a parcela da variação provocada por outros fatores não incluídos no modelo de regressão.

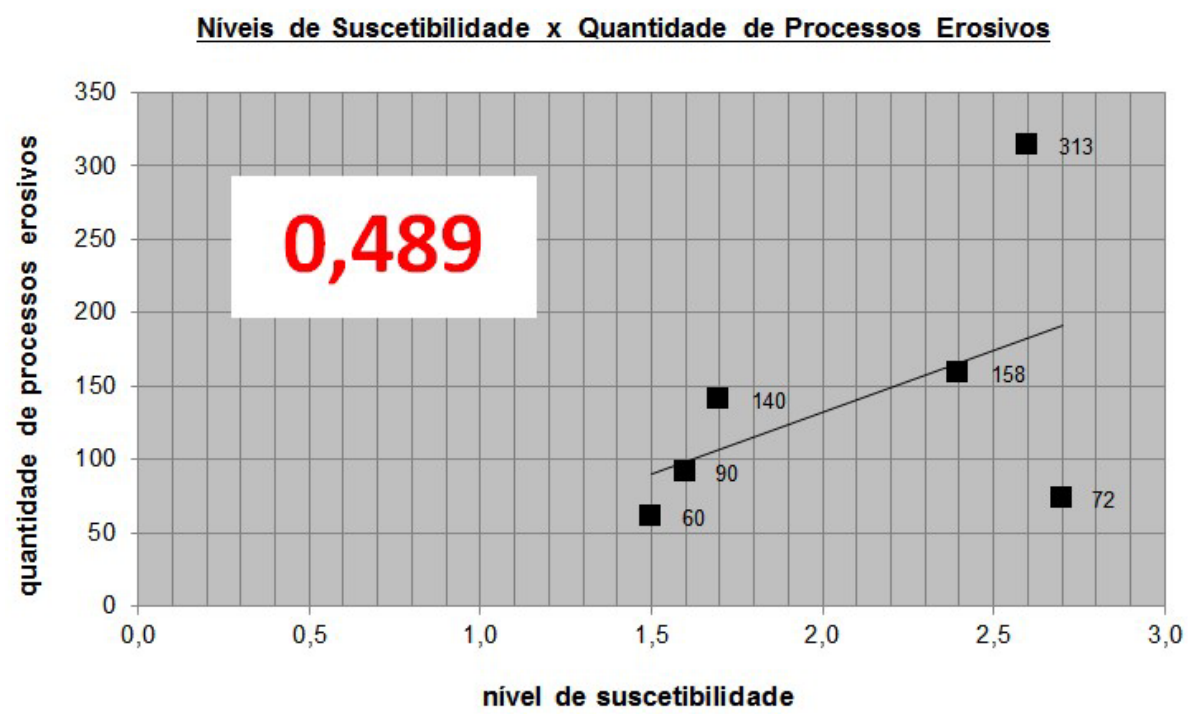

Figura 16 - Correlação linear entre níveis de suscetibilidade e quantidade de processos erosivos.

\begin{tabular}{lr}
\hline \multicolumn{2}{c}{ Estatística de regressão } \\
\hline R múltiplo & 0,489067151 \\
R-Quadrado & 0,339186679 \\
R-quadrado ajustado & 0,048983348 \\
Erro padrão & 0,528471276 \\
Observações & 6 \\
\hline
\end{tabular}

ANOVA

\begin{tabular}{|c|c|c|c|c|c|c|}
\hline & $g l$ & & $S Q$ & $M Q$ & $F$ & $p$ \\
\hline Regressão & & 1 & 0,35120577 & 0,3512058 & 1,25753 & 0,2248884 \\
\hline Resíduo & & 4 & 1,11712756 & 0,2792819 & & \\
\hline Total & & 5 & 1,46833333 & & & \\
\hline
\end{tabular}

Figura 17 - Resultado das análises estatísticas feitas a partir dos dados observados de número de processos erosivos e níveis de suscetibilidade.

\section{CONSIDERAÇÕES FINAIS}

Variáveis ambientais: produção de dados mesma abordagem. Cabe dizer, portanto, que a primários

A aplicação das técnicas propostas para geração dos mapeamentos intermediários que deram origem ao mapeamento de suscetibilidade da área de estudo mostraram-se satisfatórias no que diz respeito aos resultados esperados e a escala de mapeamento proposta para o estudo em questão. Tratam-se de métodos já difundidos e testados, amplamente utilizados em estudos de produção de dados deve atender especialmente às necessidades do analista, podendo ser direcionados a observações mais específicas e de escalas com maiores níveis de detalhamento.

Para os dados de topografia, as análises feitas priorizaram características do terreno de fácil obtenção através do manuseio dos dados em SIG, além de terem relação direta com o desenvolvimento de erosões e o processo de run 
off das águas. É comum, todavia, a obtenção de outras características relevantes, como o ângulo de curvatura das vertentes. A disponibilidade das bases digitalizadas, na escala de 1:50.000, facilitou o processo de mapeamento das características topográficas. Para escalas maiores, o Estado de São Paulo não dispõe de bases vetoriais gratuitas.

A aplicação da técnica de análises de histogramas de frequência para o mapeamento de solos permitiu recobrir, através da característica de solos já existentes, áreas que não apresentavam classes de solos definidas. Tal procedimento garantiu melhores resultados na geração do mapeamento final, porém, a checagem em campo é importante para garantir a validação do dado gerado e da técnica utilizada.

Quanto aos dados de pluviometria, embora não foram testadas outras técnicas de interpolação, mais simples, para comparação, acredita-se alcançar os melhores resultados através da aplicação da krigagem, que utiliza de parâmetros estatísticos mais robustos. Um melhor resultado apenas seria alcançado se houvesse maior quantidade de dados e distribuição dos postos pluviométricos.

Já o mapeamento de uso e ocupação do solo apresentou ótimos índices de classificação das tipologias selecionadas para mapeamento. A classificação supervisionada atendeu às necessidades do mapeamento, uma vez que não foi preciso a identificação de feições pertencentes ao tecido intra-urbano.

\section{Ponderação das variáveis: análise hierárquica de pesos}

A técnica da AHP foi de extrema importância para a composição do indicador final de suscetibilidade. Pelos resultados finais, é possível observar também que a aplicação da técnica junto à classificação de suscetibilidade proposta por Crepani et al. (2001) pareceu representar a realidade do terreno quanto ao desenvolvimento de processos erosivos. A consulta com especialistas da área também foi de extrema importância, uma vez que os técnicos têm conhecimento de campo que influenciam diretamente no julgamento das variáveis analisadas. Para realização desse trabalho, foram encontradas dificuldades na obtenção de versões free de softwares específicos para aplicação da AHP. Os resultados apresentados foram modelados em
Excell, o que pode ocasionar algumas variações dos resultados obtidos. A utilização de programas estatísticos de análises hierárquica de pesos proporciona uma análise mais segura, com apresentação de cenários possíveis (dados por julgamentos prováveis entre as variáveis analisadas) e o estudo detalhado de cada cruzamento e suas respectivas ponderações.

Importante dizer também que qualquer simples alteração nos dados de entrada, como o número de especialistas consultados ou as variáveis analisadas, irá afetar diretamente o resultado final do mapeamento e dos níveis de suscetibilidade.

\section{Mapeamento de suscetibilidade à erosão}

A obtenção de informações que validassem o resultado final do indicador foi um diferencial da pesquisa. Baseado no total de processos erosivos analisados e nas classes de suscetibilidade definidas, é possível afirmar que o mapeamento final apresentou precisão de 91,36\%.

No entanto, embora o índice gerado tenha apresentado resultados satisfatórios para os objetivos propostos, ficou evidente a limitação do mapeamento final em localizar áreas de alta intensidade relacionadas à localização de maiores quantidades de registros de erosões no terreno. Uma recomendação para pesquisas futuras seria testar tal motivo, seja por meio de checagem em campo ou adaptação do balanço final das variáveis: ponderação das relevâncias de cada temática cruzada, técnicas de geoprocessamento utilizadas para os mapeamentos intermediários das variáveis ambientais selecionadas (melhores escalas, disponibilidade de dados) variáveis ambientais utilizadas na geração do indicador, número de especialistas envolvidos para julgamento final da etapa de mapeamento, aprimoramento da técnica estatística utilizada (AHP).

Por conta do método proposto e da diversidade de metodologias possíveis para mapeamento e controle do aparecimento de processos erosivos, qualquer alteração nas etapas de geração de indicador afetará diretamente o resultado final do mapeamento. Novos resultados podem ser gerados a partir de novos testes, sob novas perspectivas, consideração de novos cenários, a fim de melhorar a precisão do resultado final e aproximar os resultados gerados à realidade da região de estudo. 


\section{AGRADECIMENTOS}

Os autores desejam expressar seus agradecimentos ao SIRDEN - IPT (Seção de Investigações, Riscos e Desastres Naturais - Instituto de Pesquisas Tecnológicas - IPT) pela parceria no desenvolvimento da pesquisa e a Fundação de Apoio ao Instituto de Pesquisas Tecnológicas - FIPT pela concessão da bolsa de pós-graduação do projeto Novos Talentos.

\section{REFERÊNCIAS}

ARCGIS/ARCMAP 10.2.1.: Maps throughout this paper were created using ArcGIS ${ }^{\circledR}$ software by Esri. ArcGIS ${ }^{\circledR}$ and ArcMap $^{\mathrm{TM}}$ are the intellectual property of Esri and are used herein under license. Copyright $($ E Esri. All rights reserved.

ARNESEN, A.S.; GENOFRE, F.T.; CURTARELLI, M.P Análise da vulnerabilidade à erosão através de SIG: um subsídio ao zoneamento ecológico-econômico de Santo Amaro da Imperatriz-SC. In: SIMPÓSIO BRASILEIRO DE RECURSOS HÍDRICOS, XVIII, Campo Grande, 2009. Atas...Campo Grande: Sociedade de Recursos Hídricos.

BARBETTA, P.A. Estatística Aplicada às Ciências Sociais. Editora da UFSC. $9^{\circ}$ ed. Florianópolis, 2012.

BERRY, J.K. Cartographic modeling: the analitical capabilities of gis. In: GOODCHILD, M. Environmental modelling with GIS. Oxford: Oxford University Press, 1993. 358p.

BUI, D.T.; PRADHAN, B.; LOFMAN, O.; REVHAUG, I.; DICK, O.B. Landslide susceptibility assessment in the Hoa Binh province of Vietnam: a comparison of the LevenbergMarquardt and Bayesian regularized neural networks. Geomorphology, v. 171/172, p. 12-29, 2012.

BURROUGHS Jr., E.R. \& KING, J. G. Reduction of Soil Erosion on Forest Roads. USDA Forest Service/UNL Faculty Publications, 1989, paper 121.

CASTRO, R. A.; FERREIRA, H.L.; SANTOS, L.C.S. Erosões Às Margens da Br 222 na Cidade de Açailândia - MA. Geomorfologia Tropical e Subtropical: processos, métodos e técnicas. In: SIMPÓSIO NACIONAL DE GEOMORFOLOGIA, VI, Goiânia, 2006.

CORRÊA, C.M.; ROLOFF, G.; SILVA, I.C. Real and estimative erosion through RUSLE from forest roads in two relief conditions and four soils profile. Scientia Forestalis, Piracicaba, n. 76, p. 57-66, 2007.

CREPANI, E.; MEDEIROS, J.S.; AZEVEDO, L.G.; DUARTE, V.; HERNANDEZ, P.; FLORENZANO, T; BARBOSA, C. Sensoriamento Remoto e Geoprocessamento Aplicados ao Zoneamento Ecológico - Econômico e ao Ordenamento Territorial. Instituto Nacional de Pesquisas Espaciais - INPE, São José dos Campos, 2001.

DEVKOTA, K.C; REGMI, A.D; POURGHASEMI, H.R; YOSHIDA, K.; PRADHAN, B.; RYU, I.C; DHITAL, M.R. Landslide susceptibility mapping using certainty factor, index of entropy and logistic regression models in GIS and their comparison at Mugling-Narayanghat road section in Nepal Himalaya. Nat Hazards, v. 65, p. 135-165, 2013.

FAGUNDES, M.G. Estudo comparativo da variação da escala nos estudos de fragilidade ambiental e vulnerabilidade natural dos solos na bacia hidrográfica do Rio Jundiaí. São Paulo, 2013. Dissertação (Mestrado) Universidade de São Paulo.

FLORENZANO, T.G. Geotecnologias na geografia aplicada: Difusão e acesso. Revista do Departamento de Geografia, v. 17, p. 24-29, 2005.

GEOVISUAL - GeoKrigagem All Rights Reserved. Universidade de São Paulo - IGC, São Paulo, 2015.

HERMUCHE, P.M, GUIMARÃES, R.F.; CARVALHO, A.P.F.; MARTINS, E.S.; DRUCK, S.; CARVALHO, O.A.; SANTOS, N.B.F.; REATTO, A. Morphometry as support for pedological mapping: I. Asymmetric watersheds. Embrapa Cerrados, Planaltina, 2002.

HYUN-JOO, Oh. \& BISWAJEET, P. Application of a neurofuzzy model to landslide-susceptibility mapping for shallow landslides in a tropical hilly area. Computers \& Geosciences, v. 37, p. 1264-1276, 2011.

INSTITUTO BRASILEIRO DE GEOGRAFIA E ESTATÍSTICA (IBGE). Manual de Noções Básicas de Cartografia. Rio de Janeiro, 1998.

INSTITUTO DE PESQUISAS TECNOLÓGICAS DO ESTADO DE SÃO PAULO (IPT). Cadastramento de pontos de erosão e inundação no Estado de São Paulo. (Relatório Técnico - 364 p.). São Paulo, IPT, 2013.

KOCHENDERTER, J.N. Erosion Control In Longging Roads.Northeastern Forest Experiment Station, Upper Darby, Pa. Forest Service, U.S Department Of Agriculture. Forest Service Research Paper Ne v. 158, 1970

POURGHASEMI, H.R.; PRADHAN, B.; GOKCEOGLU, C. Application of fuzzy logic and analytical hierarchy process (AHP) to landslide susceptibility mapping at Haraz watershed, Iran. Natural Hazards, v. 63, n. 2, p. 135 - 165, 2012.

PRADHAN, B. \& LEE, S. Delineation of landslide hazard areas on Penang Island, Malasia, by using frequency ratio, logistic regression and artificial neural network models. Environ Earth Sci, v. 60, p. 1037 - 1054, 2010.

RABACO, L.M. Avaliação de Modelos de Suscetibilidade a Movimentos Gravitacionais de Massa numa Faixa de Dutos. Rio de Janeiro, 2005. 214p. Dissertação (Mestrado) Universidade Federal do Rio de Janeiro.

REGMI, A.D.; DEVKOTA, K.C.; YOSHIDA, K.; PRADHAN, B.; POURGHASEMI, H.R.; KUMAMOTO, T.; AKGUN, A. Application of frequency ratio, statistical index, and weightsof-evidence models and their comparison in landslide susceptibility mapping in Central Nepal Himalaya. Arabian Journal of Geosciences, v. 7, n. 2, p. 725 - 742, 2014.

ROSS, J. L.S. Análise Empírica da Fragilidade dos Ambientes Naturais e Antropizados. Revista do Departamento de Geografia, v. 8, São Paulo, 1994.

ROSS, J. L.S. Análise e Síntese na Abordagem Geográfica da Pesquisa para o Planejamento Ambiental. Revista do Departamento de Geografia, v. 9, São Paulo, 1995.

ROSS, J. L.S. Zoneamento Ecológico-Econômico. Workshop Metodologia de Zoneamento Ecológico-Econômico para a Região Nordeste. Fortaleza, Ceará, 2000.

SALOMÃO, F.X.T. Controle e Prevenção dos Processos Erosivos. Erosão e Conservação dos Solos: conceitos, temas e aplicações. Bertrand Brasil, Rio de Janeiro, 1999.

SOUZA, N. C; PITOMBO, C.; CUNHA, A. L.; LAROCCA, A. P. C.; ALMEIDA FILHO, G. S. Modelo de Classificação de Processos Erosivos Lineares ao Longo de Ferrovias Através de Algoritmo de Árvore de Decisão e Geotecnologias. Boletim de Ciências Geodésicas Bol. Ciênc. Geod., v. 23, n. 1, p.72 - 86, 2017.

SPÖRL, C. \& ROSS, J.L.S. Análise Comparativa da Fragilidade Ambiental com Aplicação de Três Modelos. Revista do Departamento de Geografia, n. 15, São Paulo, 2004.

Submetido em 9 de julho de 2017 Aceito em 29 de janeiro de 2019 